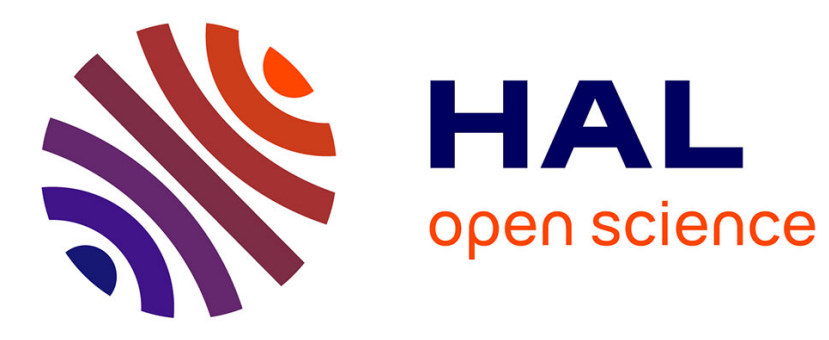

\title{
Clinical benefit of early phase clinical trial participation for advanced sarcoma patients
}

\author{
Robin L. Jones, David Olmos, Khin Thway, Cyril Fisher, Nina Tunariu, \\ Sophie Postel-Vinay, Michelle Scurr, Johann Bono, Stan B. Kaye, Ian R. \\ Judson
}

\section{To cite this version:}

Robin L. Jones, David Olmos, Khin Thway, Cyril Fisher, Nina Tunariu, et al.. Clinical benefit of early phase clinical trial participation for advanced sarcoma patients. Cancer Chemotherapy and Pharmacology, 2010, 68 (2), pp.423-429. 10.1007/s00280-010-1484-9 . hal-00640236

\section{HAL Id: hal-00640236 https://hal.science/hal-00640236}

Submitted on 11 Nov 2011

HAL is a multi-disciplinary open access archive for the deposit and dissemination of scientific research documents, whether they are published or not. The documents may come from teaching and research institutions in France or abroad, or from public or private research centers.
L'archive ouverte pluridisciplinaire HAL, est destinée au dépôt et à la diffusion de documents scientifiques de niveau recherche, publiés ou non, émanant des établissements d'enseignement et de recherche français ou étrangers, des laboratoires publics ou privés. 
Clinical benefit of Phase I participation for advanced sarcoma patients

$$
\begin{aligned}
& \text { Robin L Jones }^{1,2} \\
& \text { David Olmos }^{1,2} \\
& \text { Khin Thway }^{1} \\
& \text { Cyril Fisher }^{1} \\
& \text { Nina Tunariu }^{3} \\
& \text { Sophie Postel-Vinay }^{1,2} \\
& \text { Michelle Scurr }^{1,2} \\
& \text { Johann de Bono }^{2} \\
& \text { Stan B Kaye } \\
& \text { Ian R Judson }
\end{aligned}
$$

${ }^{1}$ Sarcoma Unit, Royal Marsden Hospital, Fulham Road, London, SW3 6JJ, UK.

${ }^{2}$ Drug Development Unit, Royal Marsden Hospital, Downs Road, Sutton, Surrey, SM2 5PT, UK.

${ }^{3}$ Radiology Department, Royal Marsden Hospital, Downs Road, Sutton, Surrey, SM2 5PT, UK

Dr Jones and Dr Olmos contributed equally.

Acknowledgments: Dr Robin Jones is supported by the Bob and Eileen Gilman Family Sarcoma Research Program. David Olmos is supported by a research fellowship from the Spanish Society of Medical Oncology (SEOM).

Correspondence: $\quad$ Dr Robin L Jones

University of Washington/ Seattle Cancer Care Alliance, 825

Eastlake Avenue E, G3630

Seattle, WA, 98109-1023. USA

Email: $\quad$ rjones@ $\quad$ seattlecca.org

Telephone: $\quad++1206.288 .7439$

Fax: $\quad++1206.288 .2054$ 


\section{Abstract:}

Purpose: Standard systemic treatment options for patients with advanced sarcoma are limited. Depending on the histological subtype, patients receive differing lines of therapy usually consisting of doxorubicin, ifosfamide and/ or trabectedin. After progression on conventional therapies some patients are offered more experimental options including Phase I clinical trials. The aim of this study was to evaluate the clinical benefit for sarcoma patients treated within the Phase I Unit of a single referral centre. Methods: The response, toxicity and outcome of sarcoma patients treated within Phase I clinical trials at the Royal Marsden between August 1998 and December 2010 was analysed. Results: One hundred and thirty three patients were treated. The median number of prior systemic therapies was 3 (range 0-6). The median age of these patients was 48.0 years (range 12.581.9), with a male/ female ratio of $71 / 62$. One patient $(0.8 \%)$ achieved a complete response and $2(1.6 \%)$ partial responses. The non-progression rate at 3 and 6 months was $31.5 \%(95 \% \mathrm{CI}, 23.4-39.6 \%)$ and $11.0 \%$ (95\%CI 5.6-16.5\%) respectively. The median progression-free survival was 2.1 months $(95 \% \mathrm{CI}, 1.7-2.5)$ and median overall survival was 7.6 months $(95 \% \mathrm{CI}, 4.8-10.4)$. Twenty-four (18.0\%) patients experienced grade 3 or 4 toxicity and $16(12.0 \%)$ stopped trial treatment due to toxicity. Conclusion: Phase I clinical trials could be considered a therapeutic option in sarcoma patients with no remaining standard treatment, due to the low risk of toxicity and the potential for clinical benefit.

Keywords: Sarcoma, drug development, response, toxicity, progression-free survival, overall survival. 


\section{Purpose}

Sarcomas are a group of heterogeneous mesodermal malignancies that encompass a diverse range of different histological subtypes [1]. For early stage sarcoma surgical resection remains the mainstay of treatment. However, in the metastatic setting, systemic treatment with chemotherapy is the main treatment option for many sarcoma subtypes. Doxorubicin and ifosfamide have shown reproducible activity in treating sarcomas [2]. Recently, trabectedin, a natural marine derived product, has emerged as an active agent, particularly in some subtypes such as myxoid/ round cell liposarcoma, refractory to anthracyclines and ifosfamide [3,4]. In addition other histological subtypes could be offered other systemic therapy regimens, such as gemcitabine and docetaxel in leiomyosarcoma and pegylated liposomal doxorubicin in angiosarcoma [2, 5].

The utility of imatinib [6] and sunitinib [7] in gastro intestinal stromal tumours (GIST) has highlighted the potential for novel targeted agents to revolutionise the treatment of a rare disease previously assigned as resistant to systemic therapy [2]. Other emerging molecularly targeted drugs have shown promising results in early trials, such as IGF1-R (Insulin-like Growth Factor-1 Receptor) monoclonal antibodies in Ewing's sarcoma [8]. However, there still remains a pressing need for new therapeutic approaches in other sarcoma subtypes.

Phase I oncology clinical trails are dose-finding and toxicity-defining studies, primarily designed to establish a safe dose and schedule for further evaluation in Phase II trials, although sometimes Phase I trials can also have pharmacokinetic or pharmacodynamic objectives as primary aims. Furthermore, antitumour activity derived from these trials is 
never considered the primary endpoint, but both patients and clinicians actively seek clinical activity.

Currently, there is little published data on the clinical benefit and risk derived by sarcoma patients treated within Phase I trials [9], although recent reports involving pooled analysis of Phase I patients suggest objective response rates between $(7.2 \%-9.4 \%)$ and a clinical benefit rate at 3 months of $(48.2 \%-53 \%)$.

At our Institution, patients (of adequate performance status) with advanced sarcoma who have no standard treatment options have traditionally been offered the possibility of participation in a Phase I clinical trial. We are unaware of any other study analysing the outcome and potential prognostic factors in sarcoma patients treated within Phase I clinical trials.

\section{Patients and methods}

This study included all consecutive sarcoma patients treated prospectively within Phase I trials in the Sarcoma and Drug Development Units at the Royal Marsden Hospital (RMH), from $1^{\text {st }}$ August 1998 and $31^{\text {st }}$ December 2009. From the hospital records we selected only patients who met the following criteria: (1) histological confirmation by an experienced sarcoma pathologist; (2) First Phase I inclusion; (3) Received at least 1 dose of the experimental agent. Several clinical parameters were collected at study entry, including sarcoma subtype, age, sex, Eastern Cooperative Oncology Group (ECOG) performance status (PS), full blood count, biochemistry (lactate dehydrogenase and albumin), number of metastatic sites, and prior oncology treatment, including the number of prior systemic therapies. Using these data, we derived the validated RMH prognostic 
score [10]. All patients included in this analysis gave written informed consent for participation in a Phase I trial and approval from the Royal Marsden Audit Committee was obtained prior to commencing this study.

Patient follow-up and response evaluation

From 2003 onwards, baseline tumour measurements were performed within 4 weeks of the first administration of study drug, between 1998 and 2002 patients had baseline measurements performed up to 8 weeks prior to first administration of study drug. Tumour measurements were repeated every 6-8 weeks during the first 6 months on trial. Tumour responses were confirmed retrospectively by a radiologist using Response Evaluation Criteria In Solid Tumours (RECIST) [11]. Toxicity and maximum grade were collected as originally recorded in the medical records, and when required the clinical trial record. In all trials included in the present analysis toxicity was graded according to the Common Terminology Criteria for Adverse Events (CTCAE), either version 2.0 or 3.0. Survival was obtained form the hospital medical records, and when necessary by contacting the general practitioner or referring institution.

\section{Statistical Methods}

Overall survival (OS) was defined as the time between Day 1 on Phase I trial and either the date of death or the last follow-up (if death was not observed during the follow-up period). For those patients with evaluable disease for response, progression-free survival time was defined by the time elapsed between day 1 on treatment until radiological progression or disease related death (which ever occurred first), if no evidence of 
progression was documented at last follow-up, PFS was censored at the time of last radiological evaluation. Analysis of the effect of potential prognostic factors was undertaken using Cox's regression to determine the subset of baseline characteristics that provided independent prognostic information as continuous variables in our series. Subsequently, prior prognostic variables in the RMH score were categorised: elevated LDH (>ULN); low albumin $(<35 \mathrm{~g} / \mathrm{L})$; and more than two sites of metastatic disease. Other numeric variables were categorised based on their deviation from standard reference. Median PFS and OS as well as their 95\% confidence intervals were determined with the Kaplan-Meier method, and survival curves were compared with the logrank test. We calculated the RMH score based on which weighted equally: LDH normal (0) versus $\mathrm{LDH}>\mathrm{ULN}(+1)$; albumin more than $35 \mathrm{~g} / \mathrm{L}(0)$ versus albumin less than $35 \mathrm{~g} / \mathrm{L}(+1)$; metastatic sites $<2(0)$ versus more than $2(+1$, see Table 1$)$. The prognostic score for each individual was derived from the sum of these three components used in the prognostic model. All $\mathrm{p}$ values were 2 sided and a significance level threshold of 0.05 was used. The analysis was performed using SPSS 15.0 (SPSS Inc., Chicago, Il).

Pathological tumour grade was included in the prognostic analysis, even though grading is not recommended for certain histological subtypes, such as GIST and extraskeletal chondrosarcoma, and for others such as malignant peripheral nerve sheath tumour it is not regarded as of prognostic value $[12,13]$

\section{Results}

Patient characteristics 
One hundred and thirty-three sarcoma patients were treated within the Royal Marsden Sarcoma and Drug Development Units between $1^{\text {st }}$ August 1998 and $31^{\text {st }}$ December 2009. The clinical characteristics of these patients are summarised in Table 1 as well as the trial treatment administered. The median age of these patients was 48.0 years (12.5-81.9). There were 71 males and 62 females. The most common histological subtype was leiomyosarcoma ( $\mathrm{n}=16,12.0 \%)$, followed by GIST and liposarcoma ( $\mathrm{n}=15,11.3 \%$ each). One hundred and twelve (84.2\%) had undergone previous surgery and 66 (49.6\%) had received prior radiotherapy. This series of patients had received a median of 3 (range 0-6) prior lines of systemic therapy, and 7 (5.3\%) received treatment with in the Phase I Unit as their first-line systemic therapy. Thirty seven (27.8\%) patients had a PS of 0 , and 7 (5.3\%) had a PS of 2. Twenty five (18.8\%) patients had a RMH score of 3. The most frequently employed trial drugs were antiangiogenic agents $(n=43,32.3 \%)$ followed by agents targeting the IGF1-R/ PI3K/ mTOR/ AKT pathway ( $\mathrm{n}=30,22.6 \%)$. Thirty seven (27.8\%) patients had a performance status of 0 , and 7 (5.3\%) had a PS of 2 . Twenty five (18.8\%) patients had a RMH score of 3

Tumour response and tolerability

One hundred and twenty seven patients were evaluable for response according to RECIST, the other 6 were GIST patients who entered a trial of SR4554, an oxidoreductive agent and hypoxia marker, and were not evaluated for response and progression-free survival. One $(0.8 \%)$ patient achieved a complete and $2(1.6 \%)$ a partial response to treatment. These responses were observed in two patients with Ewing's sarcoma treated with IGF1-R inhibitors and a patient with alveolar soft part sarcoma 
treated with an anti angiogenic agent. Stable disease was recorded as the best response in $56(44.1 \%)$ patients. Sixty-eight $(53.5 \%)$ progressed on therapy at the first radiological evaluation. The median PFS was 2.1 months $(95 \% \mathrm{CI} ; 1.7-2.5)$, and the median time to progression was 1.9 months $(95 \% \mathrm{CI} ; 1.6-2.2)$. Kaplan-Meier curves of factors with a significant association with progression-free survival are shown in Figure 1. The nonprogression rate at 3 and 6 months were $31.5 \%$ (95\%CI 23.4-39.6\%) and $11.0 \%$ (95\%CI $5.6-16.5 \%)$ respectively.

Twenty-four (18.0\%) patients experienced grade 3 or 4 toxicity and 16 (12.0\%) stopped trial treatment due to toxicity. One hundred and five patients (78.9\%) only received one Phase I trial and $28(21.0 \%)$ received further Phase I trials. Thirty four patients $(25.6 \%)$ also received further systemic therapy following treatment within the Phase I Unit. There were no treatment related deaths.

\section{Overall survival}

The median overall survival was 7.6 months (95\%CI 4.8-10.4), see Figure 1b. The 6- and 12-month OS rates were 55.4\% (95\%CI; 46.8\%- 64.0\%) and 36.3\% (95\%CI; 27.9-44.7) respectively. The 90 day mortality rate was $16 \%$ (95\% CI; 9.8-22.2).

Prognostic variables for OS are displayed in Table 2. Multivariate (MVA) analysis confirmed the independent prognostic value of serum albumin level (HR 0.89, CI 95\% 0.85-0.92, $\mathrm{p}=0.0001)$ and LDH (HR 1.72, CI 95\% 1.35-2.20, $\mathrm{p}=0.0001)$. PS and number of metastatic sites were both significant prognostic factors on univariate analysis, but failed to be significant independent factors on multivariate analysis. 
The Kaplan-Meier analysis was used to further explore the prognostic value of these factors in our series, in which: 1) patients with a low albumin $(<35 \mathrm{~g} / \mathrm{dL})$ had a shorter OS compared to those with normal Albumin (4.0 versus 12.2 months, $\mathrm{p}=0.000002$ ); 2) patients with elevated LDH $(>1 * \mathrm{ULN})$ had a poor OS compared to those with normal LDH (4.3 versus 11.6 months, $\mathrm{p}=0.001) ; 3$ ) patients with $\geq 3$ metastatic sites have a shorter OS than those with less metastatic sites of disease (4.2 versus 9.8 months, $\mathrm{p}=0.007$ ); and 4) Patients with worse performance status also presented with worse OS, (ECOG 25.2 months versus ECOG 112.4 months versus ECOG 022.8 months, $\mathrm{p}=0.005)$.

These three factors (albumin, LDH and number of metastatic sites) have been prospectively validated in the Phase I RMH score [10]. This score applied to our series identified patient groups with improved outcome: RMH score 0-1 (good prognosis) median OS 11.7 months (CI 95\% 9.0-14.4) compared to those with worse RMH score (23), who had a median OS of 4.2 months (CI 95\%3.3-5.1), $\mathrm{p}=0.003$. A Kaplan Meier curve of overall survival according to Royal Marsden Score is shown in Figure 2. Finally, we used a receiver operator curve (ROC) to estimate the ability of these three prognostic factors to predict the 90-days mortality in our series. The derived RCO curve had an area under the curve of 78\% (CI 95\% 67.5-88.5, $\mathrm{p}=0.00005$ ).

\section{Discussion}

Our study suggests that sarcoma patients with advanced disease, resistant to conventional chemotherapy can derive clinical benefit from participation in Phase I trials. This is apparent despite the number of different experimental agents administered as well as the 
heterogeneous histological subtypes included in our study. We did not perform subgroup analysis according to histological subtype, as the number of patients in each subtype was too small to provide meaningful results.

By definition, our series of patients were heavily pre-treated, having received a median of 3 prior lines of systemic treatment in addition to surgery, radiotherapy or radiofrequency ablation. Furthermore, a previous analysis of all soft tissue sarcoma patients treated at the Royal Marsden Hospital between 1991 and 2005, demonstrated a median overall survival of 12 months following first-line chemotherapy [14] and 8 months following second-line chemotherapy [15] for metastatic/ recurrent disease. The median overall survival of 7.6 months of our heterogeneous cohort of patients treated within the Phase I Unit compares favourably with these previous results. Currently, only an abstract presentation at the European Society of Medical Oncology Meeting in 2008 has reported the outcome of sarcoma patients treated within Phase I trials. This study consisted of a very small series (38 patients) and reported a median PFS of 2.7 months and a median OS of 9.2 months [9]. This study also reported a statistically significant difference in PFS (but not in OS) between patients treated with anti angiogenic agents and those treated with other agents. We did not observe a significant difference in PFS between anti angiogenic agents and those treated with drugs targeting the IGF1-R/ PI3K/ mTOR/ AKT pathway and other Phase I drugs.

Although the objective response rate was low $(\mathrm{n}=3,2.3 \%)$ in our study, the nonprogression rate of $31.5 \%$ at 3 months is encouraging in the context of dose finding experimental trials. A retrospective analysis of 12 clinical trials performed by the European Organisation for Research and Treatment of Cancer (EORTC) Soft Tissue and 
Bone Sarcoma Group suggested a 3 month progression-free rate of $\geq 40 \%$ would be indicative of drug activity in the second-line setting and that a 3 month progression-free rate of $\leq 20 \%$ would be indicative of drug inactivity [16].

The patients in this study tolerated treatment well, and only $16(12.0 \%)$ stopped therapy due to toxicity. It was not possible to retrospectively ascertain the features of the grade 3/ 4 toxicity observed, i.e. whether this was due more to the characteristics of the individual patients or the Phase I drugs administered. It is also important to note that there were no treatment related deaths. In addition, $28(21.1 \%)$ received more than one Phase I trials. Another $34(25.6 \%)$ patients were treated with systemic therapy (not Phase I trial) following participation in a Phase I trial.

We also found serum albumin and LDH to be independent prognostic factors for OS. Our study suggests that the RMH score could be of value in advising sarcoma patients of the potential value of Phase I trial entry.

In conclusion, our retrospective study showed that an unselected series of sarcoma patients derived clinical benefit from participation in Phase I trials, supporting the active recruitment of sarcoma patients into such trials, particularly if there is molecularly driven hypothesis for drug action. Such benefit is likely to increase with greater understanding of the biology of this complex group of diseases and the identification of patients with particular molecular targets likely to respond to specific drugs. 


\section{References}

1. Wunder JS, Nielsen TO, Maki RG, O'Sullivan B, Alman BA (2007) Opportunities for improving the therapeutic ratio for patients with sarcoma. Lancet Oncol 8(6): $513-24$

2. Clark MA, Fisher C, Judson I, Thomas JM (2005) Soft-tissue sarcomas in adults. N Engl J Med 353(7): 701-11.

3. Krikelis D, Judson I (2010) Role of chemotherapy in the management of soft tissue sarcomas. Expert Rev Anticancer Ther 10(2): 249-60.

4. Grosso F, Jones RL, Demetri GD, et al (2007) Efficacy of trabectedin (ecteinascidin-743) in advanced pretreated myxoid liposarcomas: a retrospective study. Lancet Oncol 8(7): 595-602.

5. Skubitz KM, Haddad PA (2005) Paclitaxel and pegylated-liposomal doxorubicin are both active in angiosarcoma. Cancer 104(2): 361-6.

6. Verweij J, van Oosterom A, Blay JY, Judson I, Rodenhuis S, van der Graaf W, Radford J, Le Cesne A, Hogendoorn PC, di Paola ED, Brown M, Nielsen OS (2003) Imatinib mesylate (STI-571 Glivec, Gleevec) is an active agent for gastrointestinal stromal tumours, but does not yield responses in other soft-tissue sarcomas that are unselected for a molecular target. Results from an EORTC Soft Tissue and Bone Sarcoma Group phase II study. Eur J Cancer 39(14): 2006-11.

7. Demetri GD, van Oosterom AT, Garrett CR, Blackstein ME, Shah MH, Verweij J, McArthur G, Judson IR, Heinrich MC, Morgan JA, Desai J, Fletcher CD, George S, Bello CL, Huang X, Baum CM, Casali PG (2006) Efficacy and safety 
of sunitinib in patients with advanced gastrointestinal stromal tumour after failure of imatinib: a randomised controlled trial. Lancet 368(9544): 1329-38.

8. Olmos D, Tan DS, Jones RL, Judson IR (2010) Biological rationale and current clinical experience with anti-insulin-like growth factor 1 receptor monoclonal antibodies in treating sarcoma: twenty years from the bench to the bedside. Cancer J 16(3): 183-94.

9. Albiges-Sauvin L, Gomez-Roca C, Domont J, Bahleda R, Gombos A, Armand JP, Pautier P, Le Cesne A, Soria JC, Massard C. Is there a substantial clinical benefit for sarcoma patients included in phase I trials? European Society of Medical Oncology Conference, Stockholm December 2008.

10. Arkenau HT, Barriuso J, Olmos D, Ang JE, de Bono J, Judson I, Kaye S (2009) Prospective validation of a prognostic score to improve patient selection for oncology phase I trials. J Clin Oncol 27(16): 2692-6.

11. Therasse P, Arbuck SG, Eisenhauer EA, Wanders J, Kaplan RS, Rubinstein L, Verweij J, Van Glabbeke M, van Oosterom AT, Christian MC, Gwyther SG (2000) New guidelines to evaluate the response to treatment in solid tumors. European Organization for Research and Treatment of Cancer, National Cancer Institute of the United States, National Cancer Institute of Canada. J Natl Cancer Inst 92(3): 205-16.

12. Coindre JM, Terrier P, Guillou L, Le Doussal V, Collin F, Ranchère D, Sastre X, Vilain MO, Bonichon F, N'Guyen Bui B (2001) Predictive value of grade for metastasis development in the main histologic types of adult soft tissue sarcomas: 
a study of 1240 patients from the French Federation of Cancer Centers Sarcoma Group. Cancer 91(10): 1914-26.

13. Hashimoto H, Daimaru Y, Takeshita S, Tsuneyoshi M, Enjoji M (1992) Prognostic significance of histologic parameters of soft tissue sarcomas. Cancer 70(12): 2816-22.

14. Karavasilis V, Seddon BM, Ashley S, Al-Muderis O, Fisher C, Judson I (2008) Significant clinical benefit of first-line palliative chemotherapy in advanced softtissue sarcoma: retrospective analysis and identification of prognostic factors in 488 patients. Cancer 112(7): 1585-91.

15. Minchom A, Jones RL, Fisher C, Al-Muderis O, Ashley S, Scurr M, Karavasilis V, Judson IR (2010) Clinical Benefit of Second-Line Palliative Chemotherapy in Advanced Soft-Tissue Sarcoma. Epublished in Sarcoma.

16. Van Glabbeke M, Verweij J, Judson I, Nielsen OS; EORTC Soft Tissue and Bone Sarcoma Group (2002) Progression-free rate as the principal end-point for phase II trials in soft-tissue sarcomas. Eur J Cancer 38(4): 543-9. 
Table 1. Clinical characteristics of $\mathbf{1 3 3}$ patients treated within the Royal Marsden Drug Development Unit.

\begin{tabular}{|l|l|}
\hline Characteristic & Number (\%) \\
\hline Age & 48.0 years \\
Range & $12.5-81.9$ years \\
\hline Gender & \\
Male & $71(53.4)$ \\
Female & $62(46.6)$ \\
\hline Histological subtype & $16(12.0)$ \\
Leiomyosarcoma & $15(11.3)$ \\
GiST & $15(11.3)$ \\
Liposarcoma & $12(9.0)$ \\
Chondrosarcoma & $9(6.8)$ \\
Synovial sarcoma & $8(6.0)$ \\
Fibrosarcoma & $5(3.8)$ \\
Osteosarcoma & $5(3.8)$ \\
MPNST & $5(3.8)$ \\
MFH & $5(3.8)$ \\
Solitary fibrous tumour & $4(3.0)$ \\
\hline Histoolar soft part sarcoma & $24(18.0)$ \\
\hline
\end{tabular}




\begin{tabular}{|c|c|}
\hline Low grade & $27(20.3)$ \\
\hline Intermediate grade & $40(30.1)$ \\
\hline High grade & $37(27.8)$ \\
\hline Unknown/Unclassified & $29(21.8)$ \\
\hline \multicolumn{2}{|l|}{ Previous surgery } \\
\hline Yes & $112(84.2)$ \\
\hline No & $21(15.8)$ \\
\hline \multicolumn{2}{|l|}{ Previous radiotherapy } \\
\hline Yes & $66(49.6)$ \\
\hline No & $67(50.4)$ \\
\hline \multicolumn{2}{|l|}{ Previous systemic therapy } \\
\hline 0 & $7(5.3)$ \\
\hline 1 & $33(24.8)$ \\
\hline 2 & $26(19.5)$ \\
\hline 3 & $35(26.3)$ \\
\hline 4 & $18(13.5)$ \\
\hline 5 & $9(6.8)$ \\
\hline 6 & $5(3.8)$ \\
\hline \multicolumn{2}{|c|}{ Time from diagnosis to metastatic disease* } \\
\hline Median & 15.5 months \\
\hline Range & 0-191.8 months \\
\hline $\begin{array}{l}\text { Time from metastatic disec } \\
\text { Median }\end{array}$ & 18.6 months \\
\hline
\end{tabular}




\begin{tabular}{|l|l|}
\hline Range & $0.3-145.9$ months \\
\hline Drug class & $43(32.3)$ \\
Anti angiogenic & $30(22.6)$ \\
IGF1-R/ PI3K/ m TOR/ AKT pathway & $16(12.0)$ \\
Novel cytotoxic & $13(9.8)$ \\
DNA synthesis and repair & $13(9.8)$ \\
Growth factor receptor inhibitor & $9(6.8)$ \\
Cell cycle and apoptosis & $6(4.5)$ \\
Oxidative metabolism & $3(2.3)$ \\
Biological & $31(23.3)$ \\
\hline Performance status & $25(18.8)$ \\
0 & $89(66.9)$ \\
1 & $7(5.3)$ \\
\hline 2 & $20(15.0)$ \\
\hline RMH Score & $57(42.9)$ \\
\hline
\end{tabular}

*NOTE: 14 patients did not have metastatic spread, but presented with locally advanced refractory/relapsing disease. 
Table 2. Univariate and multivariate analysis of prognostic factors for overall survival.

\begin{tabular}{|c|c|c|c|c|}
\hline \multirow[t]{2}{*}{ Factor } & \multicolumn{2}{|c|}{ Univariate analysis } & \multicolumn{2}{|c|}{ Multivariate analysis } \\
\hline & $\begin{array}{l}\text { Significance } \\
\text { p value }\end{array}$ & $\begin{array}{l}\text { Hazard ratio } \\
(95 \% \mathrm{CI})\end{array}$ & $\begin{array}{l}\text { Significance } \\
\text { p value }\end{array}$ & $\begin{array}{l}\text { Hazard ratio } \\
(95 \% \mathrm{CI})\end{array}$ \\
\hline Age & 0.89 & $1.00(0.99-1.01)$ & NS & \\
\hline Sex & 0.45 & $1.16(0.79-1.70)$ & NS & \\
\hline $\begin{array}{l}\text { Performance } \\
\text { status } \\
0 \\
1 \\
2\end{array}$ & $\begin{array}{l}0.007 \\
0.009 \\
0.008\end{array}$ & $\begin{array}{l}1.82(1.16-2.85) \\
3.36(1.37-8.24)\end{array}$ & NS & \\
\hline $\begin{array}{l}\text { Number } \\
\text { previous lines } \\
\text { of therapy }\end{array}$ & 0.07 & $1.12(0.99-1.26)$ & NS & \\
\hline $\begin{array}{l}\text { Histological } \\
\text { grading* } \\
\text { Low } \\
\text { Intermediate } \\
\text { High }\end{array}$ & $\begin{array}{l}0.002 \\
0.704 \\
0.003\end{array}$ & $\begin{array}{l}1.12(0.63-1.97) \\
2.38(1.34-4.25)\end{array}$ & NS & \\
\hline Albumin & 0.0001 & $0.89(0.85-0.92)$ & 0.0001 & $0.89(0.85-0.92)$ \\
\hline LDH & 0.000004 & $1.72(1.34-2.17)$ & 0.0001 & $1.72(1.35-2.20)$ \\
\hline Number of & 0.009 & $1.27(1.06-1.53)$ & 0.12 & $1.17(0.96-1.42)$ \\
\hline
\end{tabular}


metastatic sites

NS: $\quad$ Not significant

95\% CI: $\quad 95 \%$ confidence interval

*NOTE $=$ Tumor grade at diagnosis not available in 29 patients

Figure 1.Prognostic factors for progression-free survival in sarcoma patients $(n=127)$ treated within Phase I trials.

1a. Albumin

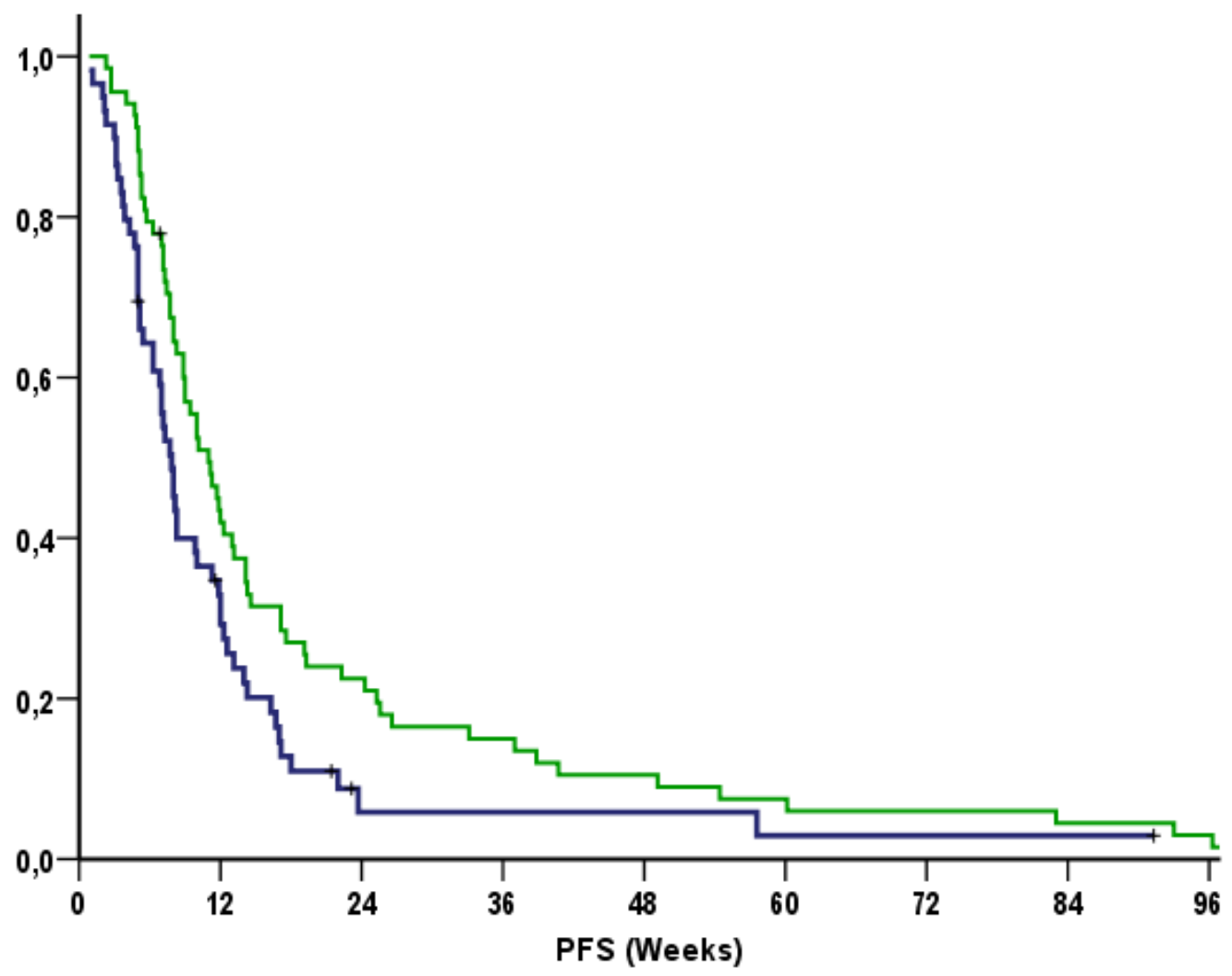

Green line: albumin $\geq 35 \mathrm{~g} / \mathrm{l}(\mathrm{n}=68)$ 
Blue line: albumin $<35 \mathrm{~g} / \mathrm{l}(\mathrm{n}=59)$

$\mathrm{P}=0.019$

1b. $\mathrm{LDH}$

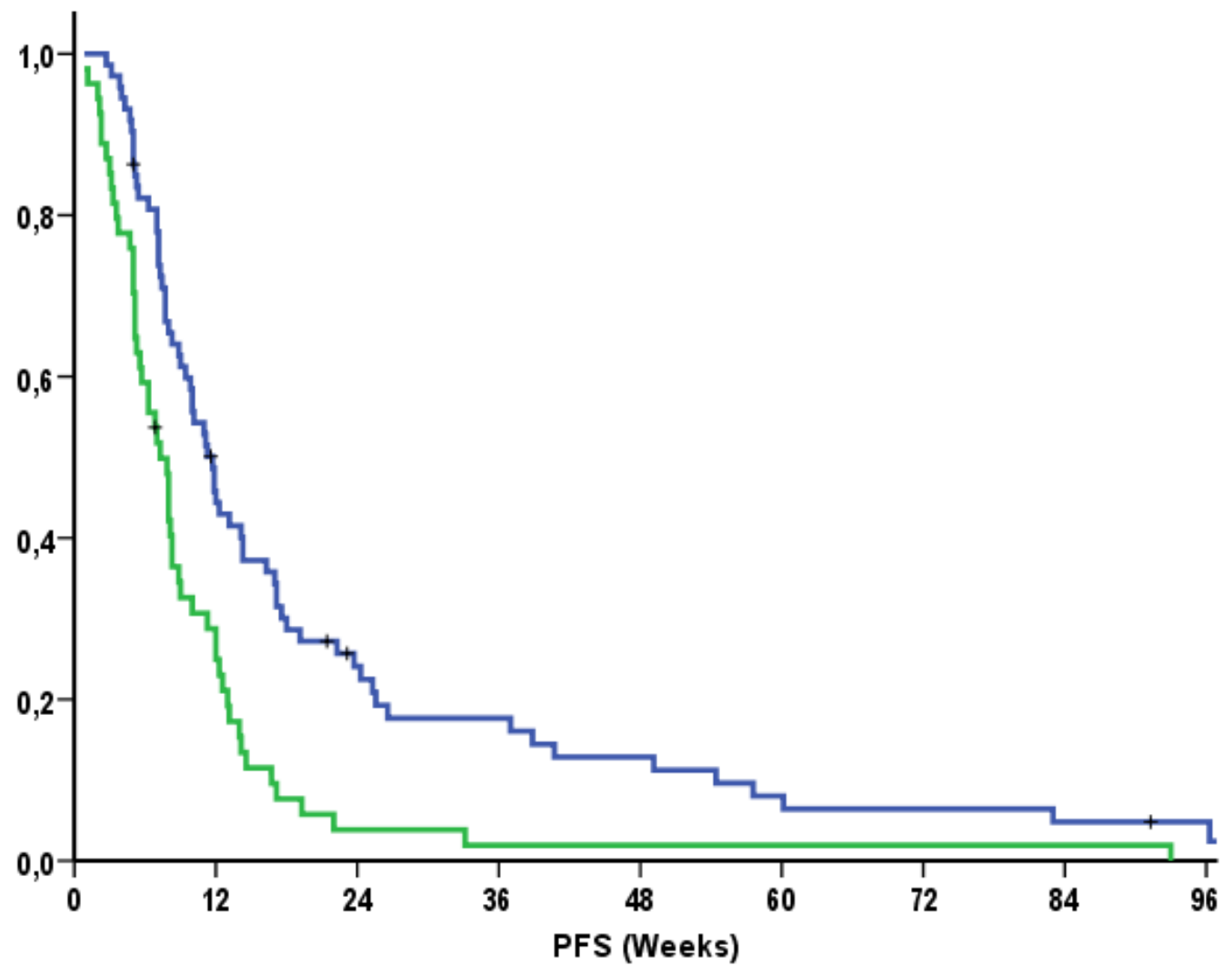


Blue line: Normal LDH ( $\mathrm{n}=73)$

Green line: Elevated LDH ( $\mathrm{n}=54)$

$\mathrm{P}=0.0002$

1c. Albumin and LDH combined.

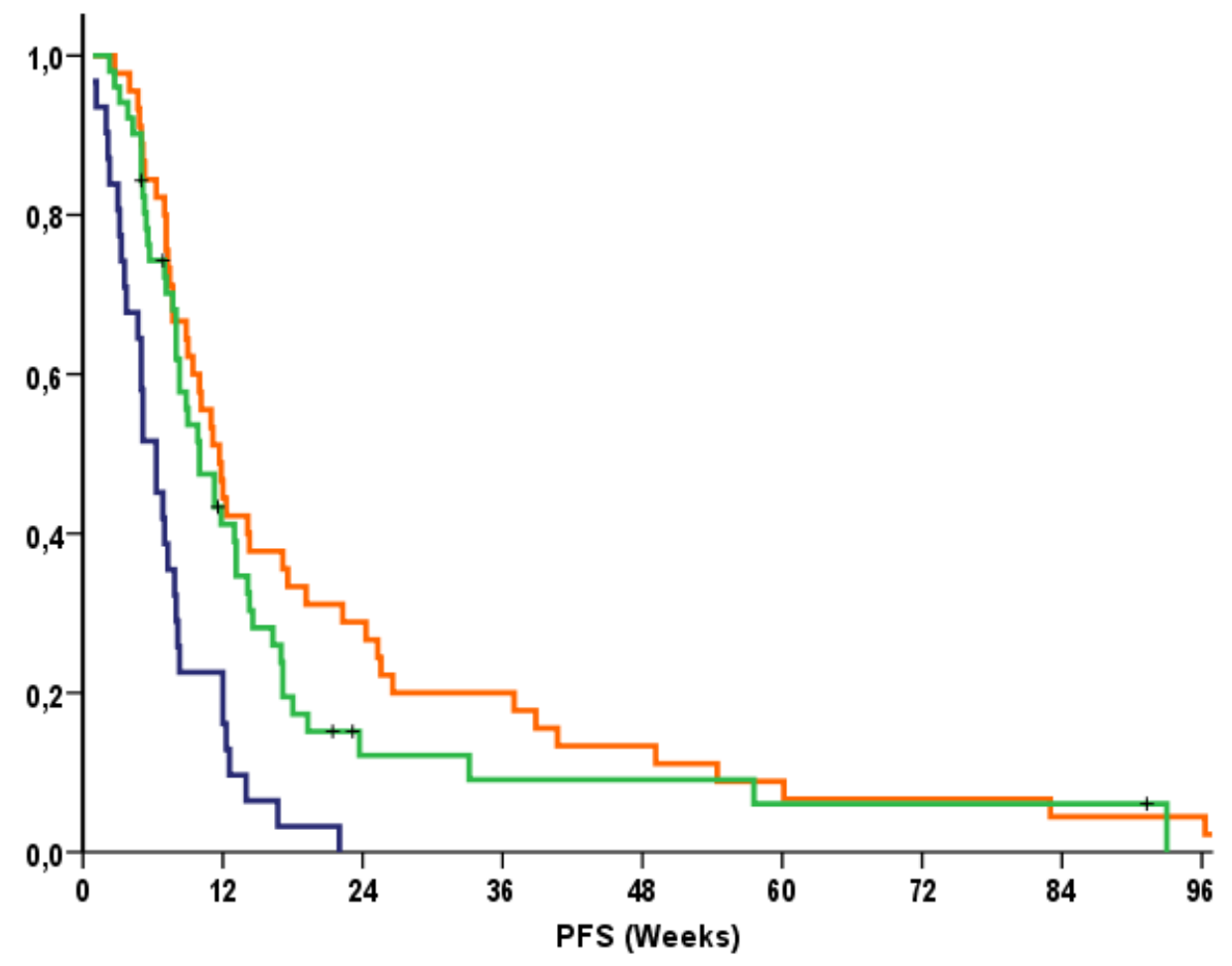


Red line: Normal LDH and albumin $\geq 35 \mathrm{~g} / \mathrm{l}(\mathrm{n}=45)$

Green line: Elevated LDH or albumin $<35 \mathrm{~g} / \mathrm{l}(\mathrm{n}=51)$

Blue line: Elevated LDH and albumin $<35 \mathrm{~g} / \mathrm{l}(\mathrm{n}=31)$

$\mathrm{P}=0.000006$

Figure 2. Kaplan Meier curve of overall survival according to Royal Marsden Score 


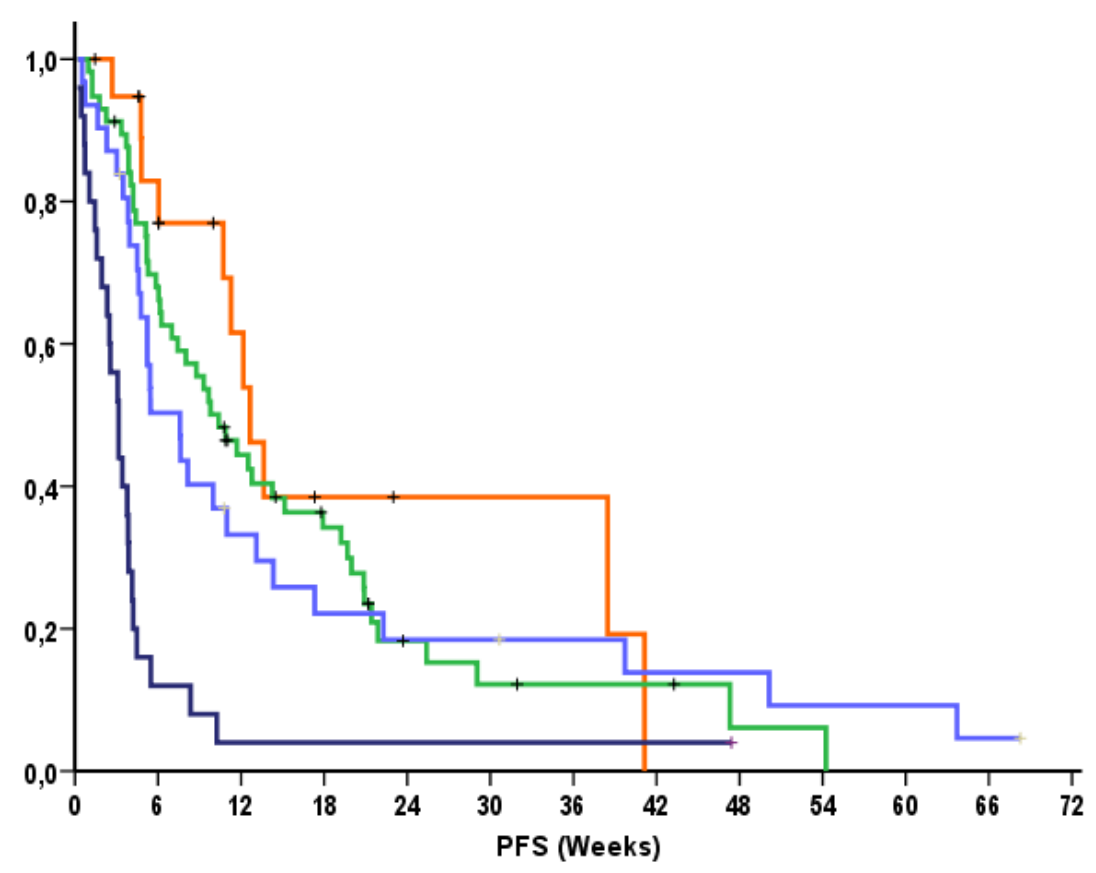

Red line: Score 0 (No adverse prognostic factors) $(n=20)$

Green line: Score 1 ( 1 adverse prognostic factors) $(n=57)$

Light blue line: Score 2 ( 2 adverse prognostic factors) $(n=31)$

Dark blue line: Score 3 ( 3 adverse prognostic factors) $(n=25)$

$\mathrm{P}=0.0000001$ 